Revue d'histoire de l'enfance « irrégulière »

Le Temps de l'histoire

19 | 2017

Abandon d'enfants et parents abandonneurs, $\mathrm{XIX} \mathrm{X}^{\mathrm{e}} \mathrm{XX \textrm {I } ^ { \mathrm { e } }}$ siècles

\title{
La délinquance des jeunes
}

Amélie Nuq

\section{OpenEdition}

Journals

Édition électronique

URL : https://journals.openedition.org/rhei/4098

DOI : 10.4000/rhei.4098

ISSN : $1777-540 \mathrm{X}$

Éditeur

Presses universitaires de Rennes

Édition imprimée

Date de publication : 22 novembre 2017

Pagination : 216-218

ISBN : 978-2-7535-6467-1

ISSN : 1287-2431

Référence électronique

Amélie Nuq, «La délinquance des jeunes », Revue d'histoire de l'enfance « irrégulière » [En ligne], 19 |

2017, mis en ligne le 22 novembre 2017, consulté le 09 septembre 2021. URL : http://

journals.openedition.org/rhei/4098; DOI : https://doi.org/10.4000/rhei.4098

(c) PUR 


\section{La délinquance des jeunes Laurent Mucchielli (dir.) 2014}

\section{Paris, La documentation française, collection "Les études ", 151 p.,} EAN : 3303331954026.

Très synthétique (151 pages) et accessible, cet ouvrage a pour but de mettre à la disposition d'un public qui ne serait pas exclusivement constitué d'universitaires un bilan des connaissances existant sur la question de la délinquance des jeunes. Il a été écrit par huit chercheur.e.s français.es et belges issu.e.s de différents champs des sciences sociales, constituant souvent des références dans leur domaine (Christophe Daadouch, Virginie Gautron, Véronique Le Goaziou, Veerle Massin, Marwan Mohammed, Laurent Mucchielli, Xavier Rousseaux et Jean-Jacques Yvorel). Trois disciplines sont convoquées pour éclairer un même objet, les transgressions des interdits posés par la loi commises par des mineur.e.s, dans une perspective successivement diachronique, sociologique et juridique. Leur contribution est irremplaçable dans un débat public toujours enclin à se saisir de façon polémique et alarmiste de la question de la délinquance juvénile, pour en souligner par exemple son développement prétendument inexorable, sa violence croissante ou son rajeunissement. Familiers de ces thématiques, les lecteurs et les lectrices de la Rhei ne seront pas surpris.es de voir déconstruites un certain nombre d'idées reçues, les auteur.e.s infirmant par exemple l'hypothèse d'une augmentation et d'un rajeunissement des comportements délinquants, ou bien mettant en évidence le fait que les différents types de délinquance étudiés témoignent davantage de la permanence que de la nouveauté des problèmes. Ainsi, les violences sexuelles commises par les mineur.e.s (par des garçons dans leur grande majorité, et généralement sur d'autres mineur.e.s) ne sont pas nouvelles dans les pratiques, mais bien plutôt dans la dénonciation et la judiciarisation qu'elles suscitent de façon croissante (chapitre 5).

La méthode utilisée consiste à confronter discours, pratiques institutionnelles et comportements; c'est notamment le cas dans les trois premiers chapitres qui replacent la délinquance juvénile dans le temps long de l'histoire. Xavier Rousseaux et Veerle Massin relèvent le défi consistant à faire l'archéologie d'un phénomène qui est autant une réalité qu'une construction sociale en brossant un panorama de l'évolution des violences juvéniles, depuis la fin 
du Moyen Âge à nos jours, en moins de 10 pages (chapitre 1). Ils soulignent que si, à l'époque médiévale, la violence isolée des jeunes inquiète peu, une nouvelle conception de la dangerosité juvénile naît en Angleterre à la fin du $\mathrm{XVIII}^{\mathrm{e}}$ siècle autour de la montée de la peur du vol. Celle-ci est liée à la dissolution de la sociabilité traditionnelle du travail par l'apprentissage sous les coups de boutoir de l'industrialisation. Dans les années 1830 et 1840, la délinquance juvénile apparaît comme un problème social nécessitant des réponses étatiques: le jeune devient l'archétype du danger social, un parangon du crime qui doit être contrôlé et enfermé dans des « écoles correctionnelles » et des pénitenciers pour jeunes. Un nouveau champ de savoirs et d'actions prend ainsi forme sous la Restauration et la monarchie de Juillet, posant les bases d'une rhétorique qui sera ensuite régulièrement recyclée " de Gavroche aux Blousons noirs ", en passant par les Apaches de la Belle Époque (chapitre 2). Notons sa grande pauvreté intellectuelle et scientifique: Jean-Jacques Yvorel montre que philanthropes et spécialistes mobilisent les mêmes schémas explicatifs et les mêmes trames descriptives, décrivant finalement peu les formes de la délinquance des mineurs et se nourrissant d'un petit nombre d'observations, le plus souvent indirectes, que l'on retrouve d'un ouvrage à l'autre. La presse et la littérature de fiction (Stendhal, Chateaubriand, frères Goncourt, Moreau-Christophe...) jouent d'ailleurs un rôle dans le façonnage de ce "problème social » de la délinquance juvénile, souvent réduit aux figures de la prostituée et du vagabond.

La question des sources est décisive: si les historien.ne.s éprouvent des difficultés à mesurer l'évolution des phénomènes de délinquance dans le temps sur la base des seules archives judiciaires, les chercheur.e.s contemporain.e.s disposent d'outils permettant de dépasser les seules statistiques émanant de la police et de la justice, comme les enquêtes de délinquance auto-déclarée. Laurent Mucchielli est ainsi en mesure d'affirmer dans le chapitre 3 qu'il n'y a globalement pas eu de croissance spectaculaire de la délinquance des mineur.e.s du point de vue des institutions qui la prennent en charge depuis les années 1970 ou que la forte augmentation des actes à caractère violent constatée dans les statistiques de police repose en réalité sur des faits de faible gravité. Lauteur examine ensuite (chapitre 4) les " carrières » des jeunes délinquant.e.s, caractérisées par une grande diversité des comportements et des parcours. On pourra être étonné.e d'apprendre que $75 \%$ des adolescent.e.s interrogé.e.s dans les enquêtes de délinquance auto-déclarée reconnaissent avoir un jour commis 
une infraction (bagarre de collégien.ne.s, petit vandalisme, vol dans un magasin, fraude dans les transports...). Mais comme le montre Laurent Mucchielli, il y a peu de points communs entre des adolescent.e.s en grande difficulté psychologique, des préadolescent.e.s commettant des transgressions peu graves dans l'entraînement d'un petit groupe et des jeunes garçons issus de milieux populaires précaires vivant dans les « quartiers sensibles » des agglomérations cumulant exclusion socio-économique et mauvaise réputation. Dans ce cas, la délinquance est une activité professionnelle de substitution marquée par la contrainte, l'incertitude et la précarité, en particulier dans les premiers étages du trafic de drogue (guetteurs, vendeurs et " charbonneurs » payés à la journée ou à l'heure, surveillés par leurs employeurs et soumis à la menace permanente d'une intervention policière).

Dans un contexte de cumul de désavantages sociaux et spatiaux (ségrégation, inactivité, précarité, discrimination) structurant la vie familiale, l'expérience scolaire et celle de la rue, l'appartenance à une «bande » fournit de puissants mécanismes compensatoires. Comme le montre Marwan Mohammed dans une contribution passionnante (chapitre 6), si les bandes incarnent une menace pour la cohésion sociale et la sécurité quotidienne, elles ont une fonction opposée pour ceux qui y participent: elles intègrent, pansent et compensent certaines plaies individuelles et permettent de gérer collectivement l'échec (scolaire, notamment) et la disqualification sociale. La mutation apparente des bandes - des « Blousons noirs " aux "Noirs en blousons " - reflète en fait un demisiècle de changement social et de mutation de la rue, sous les effets conjugués de la généralisation de la scolarisation secondaire, de la dégradation socio-économique, de l'arrivée des drogues et de l'émergence de la question ethno-raciale, le jeune délinquant étant dorénavant moins vu comme un fils d'ouvrier que comme un descendant d'immigré.

Les deux derniers chapitres, qui s'attachent à décrire du point de vue juridique la postérité de l'ordonnance du 2 février 1945 et les modes de prises en charge actuels des jeunes délinquant.e.s, viennent compléter ce panorama clair, synthétique et utile, qui est un "petit » livre à mettre entre toutes les mains.

Amélie Nuq 